\title{
Trilayer Josephson junctions Produced by Atomic Layer-By-Layer FORCE (Flexible Oxide Reaction Controlled Epitaxy)
}

Final Report

CRADA No. TC-0358-92

Date: September 30,1995 TACT: Materials

Revision:

\section{A. Parties}

The project is a relationship between the Lawrence Livermore National Laboratory (LLNL) and Varian Associates.

University of California

Lawrence Livermore National Laboratory

7000 East Avenue

Livermore, CA 94550

Varian Associates

3075 Hansen Way

Palo Alto, CA 94304-1025

\section{B . Project Scope}

Lawrence Livermore National Laboratory is working with Varian Associates to lay the groundwork for the routine, reproducible fabrication of high-temperature superconducting trilayer structures.

The objectives of this program are:

To identify high temperature superconducting materials, metallic and insulating barrier materials and associated substrate and electrode materials for engineered trilayer structures that can provide Josephson Junction devices with desired characteristics for sensor or electronic circuit use.

To identify and test potentially useful analysis techniques and to provide data appropriate for the validation and analysis of the input materials, trilayer structures and completed JJ devices.

To integrate the analysis results with the existing Varian data base to optimize the growth and fabrication process to obtain more reproducible devices actoss each chip and from chip to chip.

These objectives were defined by a detailed set of milestones for both Lawrence Livermore National Laboratory and Varian Associates all of which have been meet. The timing of the milestones was revised midway through the CRADA term to allow a longer time to pursue the objectives at no additional cost to either partner.

\section{Technical}

The original goals of the program were maintained through the term of the CRADA. During this period significant progress has been made in understanding the characteristics of the superconducting materials and some combinations capable of fabrication into electronic device arrays have been made. The utility of available analysis techniques for problem solving and 


\section{DISCLAIMER}

This report was prepared as an account of work sponsored by an agency of the United States Government. Neither the United States Government nor any agency thereof, nor any of their employees, makes any warranty, express or implied, or assumes any legal liability or responsibility for the accuracy, completeness, or usefulness of any information, apparatus, product, or process disclosed, or represents that its use would not infringe privately owned rights. Reference herein to any specific commercial product, process, or service by trade name, trademark, manufacturer, or otherwise does not necessarily constitute or imply its endorsement, recommendation, or favoring by the United States Government or any agency thereof. The views and opinions of authors expressed herein do not necessarily state or reflect those of the United States Government or any agency thereof. 


\section{DISCLAIMER}

Portions of this document may be illegible in electronic image products. Images are produced from the best available original document. 
quality control is understood and the results of appropriate analyses have been incorporated into film fabrication. An overall level of understanding has been achieved that sets the stage for routine fabrication of electronic devices using these superconducting thin films. There remains a continued need by Varian Associates to improve materials combinations and manufacturing techniques in order to easily provide high quality film layer combinations for fabrication into electronic devices.

\section{Partner Contribution}

Varian Associates used their unique capabilities to fabricate high temperature superconducting thin films layered with other non-superconducting materials and to evaluate them for their suitability for fabrication into electronic devices. These films were made in several configurations using a variety of materials in the superconducting films. Varian Associates have refined their fabrication process as a better understanding of the results of the film deposition grew from the analyses performed at Lawrence Livermore National Laboratory. These activities constituted Varian Associates main deliverables and were performed at the expected level. Varian Associates are now making the highest quality films of high temperature superconducting layered structures available in the world and are the only growers capable of supplying sufficient uniformity across a film to fabricate multiple electronic devices in an array. Additional development at Varian Associates is required to bring these films to their full commercial potential.

\section{E. Financial $(\$ K)$}

$\begin{array}{ll}\text { Federal } & \$ 1,000,000 \\ \text { Non-Federal } & \$ 1,000,000 \\ \text { Total Funding } & \$ 2,000,000\end{array}$

Expenditures on this project were made according to the original plan with one deviation. At the mid point of the funding period the length of time to perform the CRADA goals was extended for six months at no additional cost. All of the funds were spent in accordance with the modified schedule. 
E. Financial (\$K) continued
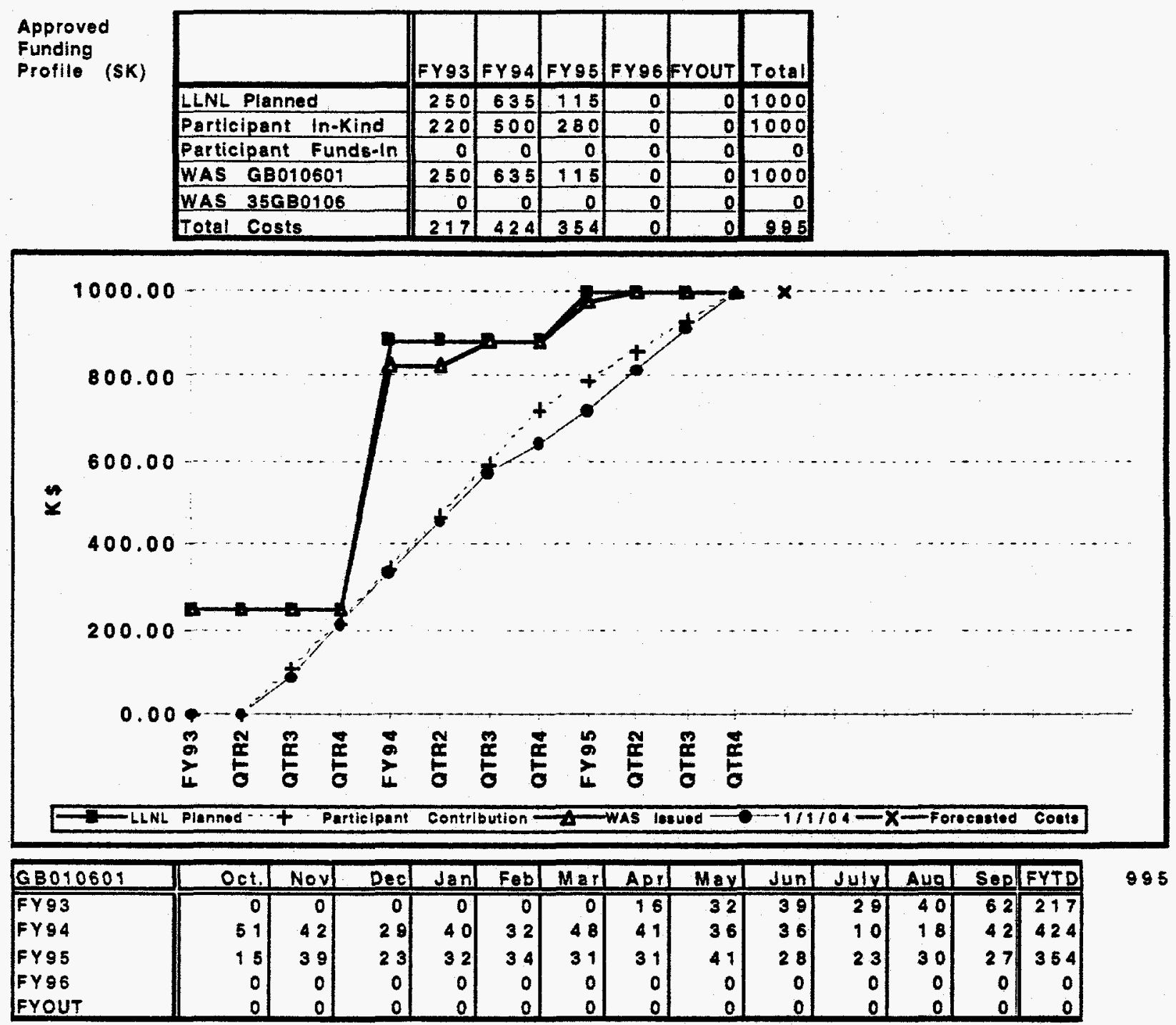

\section{F. Documents/Reference List}

\section{Reports}

Quarterly Report for Reporting period 4/1/93 - 6/30/93

Quarterly Report for Reporting period 7/1/93 - 9/30/93

Quarterly Report for Reporting period 10/1/93 - 12/31/93.

Quarterly Report for Reporting period 1/1/94 - 3/31/94

Quarterly Report for Reporting period 4/1/94 - 6/30/94

5/17/94 Annual Project Review w/viewgraphs.

Quarterly Report for Reporting period 7/1/94 - 9/30/94

with CRADA Change Report for a No cost extension

Quarterly Report for Reporting period 10/1/94 - 12/31/94.

Quarterly Report for Reporting period 1/1/95 - 3/31/95.

Quarterly Report for Reporting period 4/1/95 - 6/30/95

4/14/95 Annual Project Review w/viewgraphs

Final Report 


\section{Published Work}

R.H. Howell, A. Chaiken, R.G. Musket, M.A. Wall, M. Balooch, D Phinney, and M.J. Fluss, J.N. Eckstein, I. Bozovic, and G.F. Virshup, "Microanalytical Study of Defect Formation in Thin Bismuth Strontium Calcium Copper Oxide Films" in Oxide Superconducting Physics and Nano-Engineering, ed. D. Pavuna, SPIE, Bellingham WA. vol 2158, p182 (1994)

I. Bozovic, J.N. Eckstein, G.F. Virshup, A. Chaiken, M.A. Wall, R.H. Howell, and M.J. Fluss, "Atomic Layer Engineering of Cuprate Superconductors" Journal of Superconductivity 7, 187 (1994)

\section{In Preparation}

A. Chaiken, R.H. Howell, M. Wall, I. Bozovic, J.N. Eckstein, G.F. Virshup, "Transmission Electron Study of Heteroepitaxial Growth in $\mathrm{Bi}_{2} \mathrm{~S}_{2} \mathrm{CaCu}_{2} \mathrm{O}_{8}$ and Related Materials"

R.H. Howell, A. Chaiken, I. Bozovic, J.N. Eckstein, "Microanalytical Determination of Defect Properties in Thin Bismuth Strontium Calcium Copper Oxide Films"

\section{G. Property and Proprietary Information}

All personal property has been returned to the original owners and all proprietary information in the possession of second parties has been destroyed.

\section{H. Acknowledgment}

Participant's signature of the final report indicates the following:

1) The Participant has reviewed the final report and concurs with the statements made therein.

2) The Participant agrees that any modifications or changes from the initial proposal were discussed and agreed to during the term of the project.

3) The Participant certifies that all reports, inventions disclosures and patent applications attributable to the project are completed or are in process and a list is attached to this report.
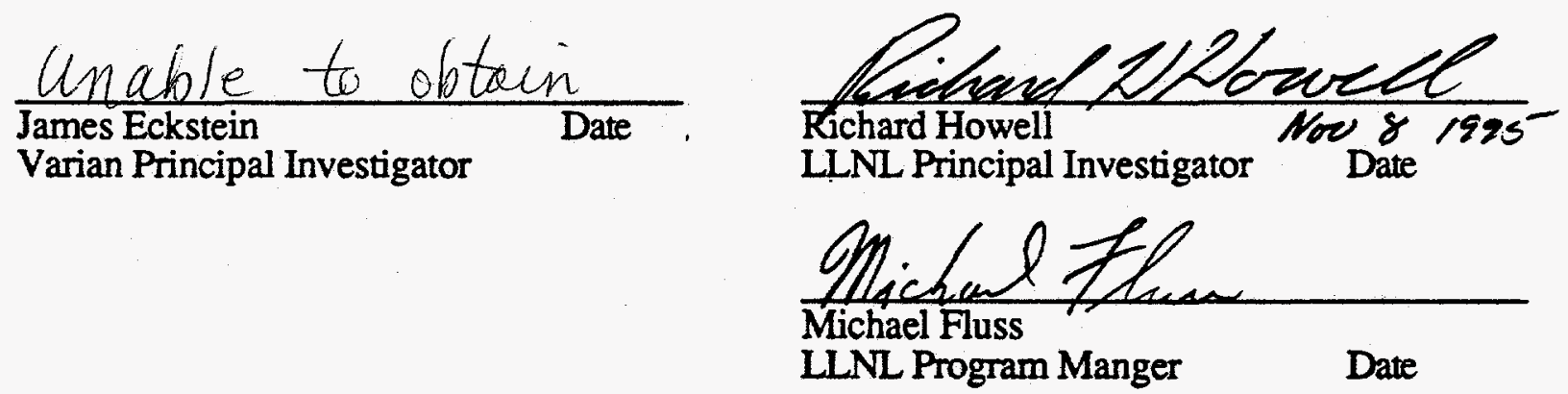

Attachment I - Project Accomplishments Summary 


\title{
Trilayer Josephson junctions Produced bt Atomic Layer-By-Layer FORCE (Flexible Oxide Reaction Controlled Epitaxy)
}

Project Accomplishments Summary (Attachment I)

CRADA No. TC-0358-92

Date: September 30,1995 $\quad$ TACT: Materials $\quad$ Revision:

\section{A. Parties}

The project is a relationship between the Lawrence Livermore National Laboratory (LLNL) and Varian Associates.

\author{
University of California \\ Lawrence Livermore National Laboratory \\ 7000 East Avenue \\ Livermore, CA 94550 \\ Varian Associates \\ 3075 Hansen Way \\ Palo Alto, CA 94304-1025
}

\section{B . Background}

Josephson junctions are the basic component of electronic devices and sensors operating in the superconducting state. They are the building blocks of Superconducting QUantium Interference Device, SQUID, high sensitivity magnetic sensors and are the elemental device in high speed superconducting digital electronics. The development of superconducting digital electronics using arrays of Josephson junctions in low transition temperature superconductors is presently in a period of rapid innovation. An increasingly complex and sophisticated set of logic families have been developed for a variety of uses, ranging from digital signal processing to general purpose microprocessors. There is strong interest in extending these developments to materials having high temperature superconductivity in order to ease the constraints imposed by low temperature cryogenic systems.

At present there are two basic approaches to high temperature superconductor Josephson junction fabrication. In one approach, measures are taken to produce "major" grain boundaries at specific locations in the thin films. This technique relies on reduced superconducting properties at the programmed grain boundary, and devices patterned out of such films can be Josephson junctions. Varian has pioneered a second, more useful approach in which Josephson junctions are made by standard patterning techniques commonly used in electronic manufacturing. In these junctions current flows vertically from the film substrate through layered single crystal films in which the electronic properties of thin barrier layers are engineered so as to control the electronic properties of transport from the base to counter electrode layers. Such multilayer structures are much easier to insert in existing low temperature superconducting fabrication processes than the grain boundary junctions. 
Varian Associates FORCE film deposition process provides the detailed control to fabricate materials molecular layer at a time. This enables Josephson junction configurations based on novel materials systems such as those with precisely placed dopant atoms or with layers of second phases interspersed in the layers of high temperature superconducting material. At the beginning of this project there were significant questions about the physics controlling the optimum choice of superconducting and non-superconducting layers for Josephson junction design. There were also questions about the details of the control of the fabrication process and the critical factors controlling the uniform quality of the films. These were the questions are addressed by the project described below.

The use of engineered barriers in trilayer Josephson junctions offers the potential of obtaining device properties that are determined by the properties of materials with engineered structure and atomic placement. Ultimately, improved control of materials synthesis offers the promise of obtaining tight control over device properties fabricated on practical sized wafers through process and materials certification. The first phase is to develop manufacturing technology for constitutive materials and geometries that will make high transition temperature superconducting material routinely available in a form useful to parties interested in the development of superconducting digital circuits or other devices based on Josephson junction technologies. Successful development of engineered barriers will have a major impact in the area of microelectronics and photonics by supplying materials for use in the design of high speed, high density, ultra-low power-density digital electronics.

\section{Description}

This project brings together two partners with complementary capabilities. Varian Associates is an international, high-technology electronics company with annual sales of over one and one half billion dollars. The ALL-FORCE, (Flexible Oxide Reaction Controlled Epitaxy) epitaxial deposition technique has been pioneered at the Varian Research Center, an undisputed world leader in this technology. ALL-FORCE has made possible synthesis of state-of-the-art thin films of various stable and metastable superconducting oxides and artificial structures. It demonstrates the ability to engineer barrier and junction properties over a broad range of materials properties, including composites containing metastable compounds. LLNL has world-recognized capabilities to characterize and model these materials, thus identifying the proper range of key structural parameters for device optimization.

By combining our capabilities we jointly addressed the questions about the physics controlling the optimum choice of superconducting and barrier layers and those about the details of the control of the fabrication process and the identity of critical quality factors.

Our specific objectives were:

To identify high temperature superconducting materials, metallic and insulating barrier materials and associated substrate and electrode materials for engineered trilayer structures that will provide Josephson junction devices with desired characteristics for sensor or electronic circuit use.

To identify and test potentially useful analysis techniques and to provide data appropriate for the validation and analysis of the input materials, trilayer structures and completed JJ devices.

To integrate the analysis results with the existing Varian data base to optimize the growth and fabrication process to obtain more reproducible devices actoss each chip and from chip to chip.

To accomplish these objectives Varian produced approximately 500 new films for test and calibration. Selected films were made in new materials combinations and geometries for investigation of Josephson junction behavior. Many of these combinations were formed by 
doping Dy for $\mathrm{Ca}$ in a molecular layer in the $\mathrm{Bi}_{2} \mathrm{Sr}_{2} \mathrm{CaNCuN}+1 \mathrm{O}_{4}+2 \mathrm{~N}$ in order to form a nonsuperconducting barrier layer necessary for a Josephson junction. In these films a variety of barrier thicknesses were tested along with multiple barriers and many doping concentrations. About 30 percent of these were then patterned into an array of devices using standard electronic processing techniques. Other films were used for calibration of the epitaxial deposition system, for analysis of film characteristics and for tests of the basic properties of new materials formulations or doping levels.

Some of the analytical tasks required close coordination between Varian and Livermore. For instance all of the device samples have undergone basic measurements of the transport of electrical current at Varian. Some of these were then selected for measurement under high magnetic fields at Livermore. Also strontium titanate substrate material was routinely inspected at Varian and selected pieces were microscopically analyzed at Livermore and returned to the Varian process stream.

A main Livermore responsibility was to test the starting material and finished films and devices using the extensive capabilities for analysis available at Lawrence Livermore National Laboratory. To this end selected samples were analyzed by Rutherford Backscattering Spectroscopy, Secondary Ion Mass Spectroscopy, Electron Microprobe Analysis, Auger Microprobe Analysis, Ion Microprobe Spectroscopy, Scanning Tunneling Microscopy, Atomic Force Microscopy, Scanning Electron Microscopy and High Resolution Transmission Electron Microscopy. These techniques were first evaluated for their utility in providing useful information regarding either general film quality or the details of defects sometimes found after deposition. Some were then chosen for routine use in subsequent analysis. Data from all of the analytical techniques investigated were found to have value in determining the optimum conditions for film growth.

In some analyses results were obtained that were immediately applied to the film deposition process. RBS was used as a primary calibration for the strength of the molecular beams in the epitaxial deposition through out the term of the project. Advances in cleaning and fluorine acid etching of the strontium titanate substrate material were also implemented. We also developed techniques that allowed us to perform full analytical investigations of samples removed directly form the Varian process stream reducing the need for the production of special samples for analysis.

Analyses were performed to understand the quality of the deposition process and to identify the cause of flaws that could occur. TEM pictures demonstrated the high quality of the deposited films and the continuity of the non-superconducting layers essential to junction performance. RBS post analysis confirmed that expected levels of control were routinely achieved on each of the molecular beams in the system. The identification of the chemical species of defects sometimes produced during deposition required a coordinated protocol involving several techniques including RBS, AFM, STM, EMS, AMS, and SEM.

Significant advances were made in understanding the interaction of superconducting and different non-superconducting layers in single and multiple layer geometries. Varian is now capable of producing Josephson junction tunneling arrays with nearly ideal junction parameters and stacked proximity coupled junctions with uniform operation of each junction within a few percent. This easily patterned vertically conducting geometry produces the only high-temperature superconducting junction arrays with sufficient uniformity for consideration as the basis for electronic device design.

The effort has resulted in an improved understanding of materials issues affecting junction performance and detailed improvements in the film deposition process. It leads the way in to 
early application of Josephson junction arrays as voltage standards and introduces high temperature superconducting systems for serious consideration as the basis of digital electronic devices.

\section{Expected Economic Impact}

The potential economic impact of workable, easily patterned high temperature superconducting digital electronics and sensors affects the core of a multibillion dollar electronic industry. This project improves the quality of feed material into the developing ultra-fast superconducting digital electronics technology. The impact of superconducting digital electronics is preliminary and will not be fully apparent for some time. In the short term new, small markets supplied by films made by these techniques for voltage standards, sensors and research applications are emerging.

\section{E. Benefits to DOE}

DOE and the DOE defense mission accrue both direct and indirect benefits from our activity. Our CRADA has resulted in the direct improvement of Lawrence Livermore National Laboratory infrastructure through maintenance and upgrade of critical skills in thin film analysis, point defect analysis and microanalytical analysis. It has brought to consideration new techniques for microanalytical defect analysis with high impact on the needs of science based stockpile stewardship. The implementation of ultra-fast superconducting electronics and sensors has a much larger potential impact. New sensors and integrated electronics are needed in monitoring the existing stockpile of nuclear weapons. Expanding the limits of computational size and speed will impact the design, development and testing of nuclear weaponry and high speed communications will find application in the non-proliferation/test ban environment.

\section{F. Industry Area}

The successful application of Josephson junction devices in microwave devices, sensors ultra-fast digital circuitry and voltage standards opens a new market opportunity for Varian. Major product lines include radiation therapy and planning equipment for cancer treatment,; wafer fabrication equipment for the semiconductor industry; analytical instrumentation and vacuum equipment for science and industry; and electron tubes for communications, radar, electronic counter measures, science, medicine and industrial uses. High temperature superconducting devices offer promising advances in electronics, communications, computations and medical instrumentation. 
CRADA No. TC-0358.92

Attachment I

\section{G . LLNL Point of Contact for Project Information}

Mike Fluss

Program Leader

L-326

Lawrence Livermore National Laboratory

Livermore, CA 94550

510-423-6555

510-422-3360 FAX

fluss1@llnl.gov

Richard H Howell

Principal Investigator

L-280

Lawrence Livermore National Laboratory

Livermore, CA 94550

510-422-1977

501-422-7300 FAX

howell5@llnl.gov

\section{H. Company Size and Point(s) of Contact}

Varian Associates is a diversified, electronics company that designs, manufactures and markets high-technology systems and components for applications in world wide markets. Varian facilities employ approximately 8100 persons and result in over 1.5 billion dollars sales yearly.

Primary contact:

Dr. James Eckstein

Principal Investigator-Group Leader

Varian Associates

3075 Hansen Way

Palo Alto, CA 94304-1025

415-424-5081

415-424-6988 FAX

Dr. Ivan Bozovic

Varian Associates

3075 Hansen Way

Palo Alto, CA 94304-1025

415-424-6358

415-424-6988 FAX

\section{Project Examples}

Varian Associates are routinely producing high quality arrays of Josephson junctions from high temperature superconducting material. The attached figure 1 shows a typical array patterned on a film containing Dy substituted for Ca to form a junction layer in a superconducting matrix of $\mathrm{Bi}_{2} \mathrm{Sr}_{2} \mathrm{Cu}_{1} \mathrm{Ca}_{2} \mathrm{O}_{8}$. Lawrence Livermore National Laboratory contributed to Varian's success by performing advanced analysis on the films and layers as seen in the transmission electron 
micrograph shown in figure 2 and on elements of the production process as seen in the atomic force micrograph of a film substrate seen in figure 3 . In the TEM micrograph high resolution of details demonstrating the high quality of Varian films can be clearly seen in the horizontal layers of superconducting material and barrier thicker junction. The AFM micrograph was taken after etching by a technique investigated at LLNL to improve the definition of crystal planes in the substrate. The planes are easily seen running in a vertical direction in the picture.

\section{RELEASE OF INFORMATION}

This report was prepared by

\section{Richard H Howell}

Principal Investigator

L-280

Lawrence Livermore National Laboratory

Livermore, CA 94550

510-422-1977

501-422-7300 FAX

Howell5@llnl.gov

I have reviewed the attached Project Accomplishment Summary prepared by Lawrence Livermore National Laboratory and agree that the information about our CRADA may be released for external distribution.

unable to obtain

Dr. James Eckstein

Group Leader

Varian Associates

3075 Hansen Way

Palo Alto, CA 94304-1025
Date 